\section{Identification of Endonu- clease Activity in HIV-1 gp120 Preparations Pro- duced Using Baculovirus Expression Systems}

BioTechniques 23:296-299 (August 1997)

\begin{abstract}
Experiments undertaken with commer-
\end{abstract} cially available recombinantly produced human immunodeficiency virus Type 1 (HIV-1) gp120 demonstrated that the resuspended lyophilized protein, a product of the baculovirus expression system, had intrinsic nuclease activity. This nuclease activity was distinguishable from the moleculargrade bovine serum albumin that it was constituted in. The activity was thermolabile in that if the preparation was heated to $100^{\circ} \mathrm{C}$ for $10 \mathrm{~min}$, the activity was abolished, although this did not happen when it was stored at $-20^{\circ} \mathrm{C}$. The nuclease activity was also $\mathrm{Ca}^{+2}$ - and $\mathrm{Mg}^{+2}$-dependent, and had endonuclease as opposed to exonuclease activity. $\mathrm{Zn}^{+2}$ ions were found to inhibit the enzyme. The intensity of nuclease activity varied from batch to batch. A lyophilized homogenate of $\mathrm{S} f 9$ insect cells expressing the Rho baculovirus-derived red blood cell protein 4.2 (Pallidin) was also found to have nuclease activity on reconstitution. In contrast, most, though not all E. coli-produced recombinant proteins were found to be free of nuclease activity. The use of activity gels to identify the size of the nuclease contained in the gp120 preparation was limited, because despite the use of many renaturation methods, the enzyme in the gp120 preparation could not be functionally resuscitated following sodium dodecyl sulfate polyacrylamide gel electrophoresis. Immunoprecipitation studies were useful to demonstrate that nuclease activity in the gp120 preparation was functionally distinguishable from the gp120 itself. When mononuclear cells transformed with antiCD3 were concurrently incubated with gp120 (5-40 $\mu \mathrm{g} / \mathrm{mL})$, internucleosomal DNA fragments characteristic of apoptosis were demonstrated in the supernatant by DNA gel electrophoresis. In the context of HIV-1 and AIDS, where the depletion of $C D 4^{+} T$-cells has been found to be associated with apoptosis, nuclease activity intrin- sic to the gp120 preparation used in experimentation may potentially alter experimental results.

\section{INTRODUCTION}

The successful use of the insect cell/baculovirus expression strategy in the large-scale production of recombinant proteins of mammalian, insect, plant and bacterial origin has revolutionized biology, biotechnology and chemistry. This highly efficient expression system has been well characterized $(6,9,11)$, and its ubiquitous utilization and exploitation is testament to the many factors intrinsic to the system that contribute to its popularity. These include high protein expression levels, ease and speed of genetic engineering, accommodation of large DNA inserts, post-translational protein processing (e.g., glycosylation) similar to mammalian cells and ease of insect cell growth in suspension (11).

Despite years of intensive investigation and speculation concerning the specific virological and immunological mechanisms of cell death involved in human immunodeficiency virus Type 1 (HIV-1) infection (13), certain of these still remain elusive. Nevertheless, there is mounting and conclusive evidence that the process of apoptosis is at least contributory to T-cell depletion $(1,10$, 19,20).

Since the gp120 protein has been incontrovertibly linked to apoptotic cell death mechanisms in HIV-1 disease pathogenesis, and because there are dangers inherent in the purification of gp120 from cultures infected with the virus and from blood derived from $\mathrm{HIV}^{+}$donors, gp120 is often produced in the insect/baculovirus system for subsequent use in research and commercial enterprises.

In this study, which was aimed at the evaluation of putative apoptosis-blocking strategies in cultures of peripheral blood mononuclear cells (PBMC) exposed to cross-linked gp120/anti-gp120 complexes, we noted contaminating endonuclease activity in culture supernatants containing recombinant gp120 protein that had been produced in the baculovirus expression system. While not disputing the role of apoptosis in T- cell depletion in AIDS, this report is aimed at drawing attention to the baculovirus-associated endonuclease activity, which may confound the interpretation of studies addressing this phenomenon in vitro.

\section{MATERIALS AND METHODS}

\section{Use of Special Reagents}

Baculovirus-produced recombinant gp120 IIIB (Batch Nos. 93-545, 94-14, 94-276, 94-286 and 94-357) and IgGpurified rabbit anti-gp120 antibodies were obtained from Intracel (London, England, UK or Cambridge, MA, USA) and were reconstituted in sterile double-distilled water. Molecular biology-grade bovine serum albumin (BSA), which contained no deoxyribonucleases, ribonucleases, proteases or nicking activity (Boehringer Mannheim, Mannheim, Germany), was added to the reconstituted gp120 to give a final concentration of $1 \mu \mathrm{g} / \mathrm{mL}$. To confirm that the BSA was not the source of the nuclease activity in our gp120 preparation, we incubated an aliquot of BSA with $1 \mu \mathrm{g}$ DNA for $4 \mathrm{~h}$ and electrophoresed it. Visualization on an ethidium bromide-impregnated, agarose gel verified that BSA had no nuclease activity (Figure 1). Recombi-

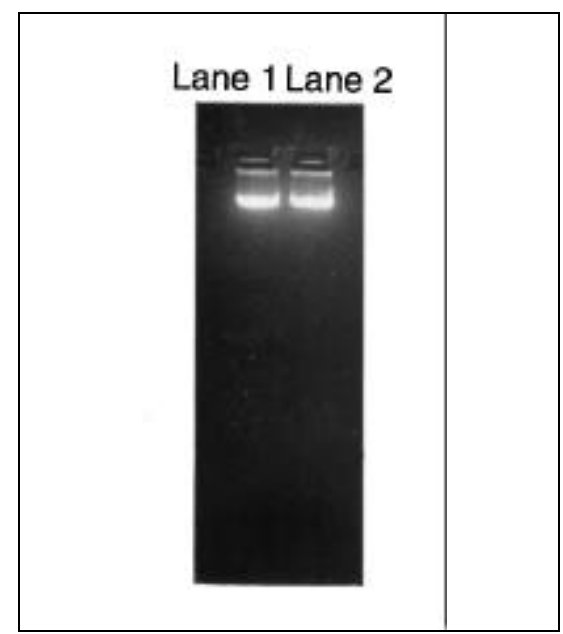

Figure 1. The effect of $4 \mu \mathrm{g}$ BSA on $1 \mu \mathrm{g}$ human DNA when co-incubated at $37^{\circ} \mathrm{C}$ for $4 \mathrm{~h}$ and subsequently size-fractionated by DNA agarose gel electrophoresis. Lane 1 shows the result of DNA incubated in endonuclease buffer alone; whereas, Lane 2 shows the outcome of DNA incubated in the presence of both endonuclease buffer and BSA $(4 \mu \mathrm{g})$. 
nant gp120, Interleukin (IL)-1 $\alpha$, IL-1ß, IL-6 and Interferon-gamma (the latter four substances all from Boehringer Mannheim) and a reconstituted homogenate of $S \mathrm{f} 9$ cells expressing Rho baculovirus-derived red blood cell protein 4.1/Pallidin (a kind gift from Dr. Mary Risinger, St. Elizabeth's Medical Center, Boston, MA) were all assessed for nuclease activity by incubation with $1 \mu \mathrm{g}$ DNA at $37^{\circ} \mathrm{C}$ for $4 \mathrm{~h}$ and subsequent DNA gel electrophoresis (8). The effect of $\mathrm{Ca}^{+2}, \mathrm{Mg}^{+2}$ and $\mathrm{Zn}^{+2}$ ions on nuclease activity was evaluated, and the endo-/exo-nature of the nuclease was determined by the co-incubation of an aliquot of gp120 with the circular plasmid pGEM $^{\circledR}$-3ZDNA (Promega, Madison, WI, USA).

\section{Cell Culture}

Enriched populations of PBMCs were isolated from the blood by density gradient centrifugation. PBMCs were transformed with an anti-CD3 monoclonal antibody (DK-2600; DAKO A/S, Glostrup, Denmark). Where solid-

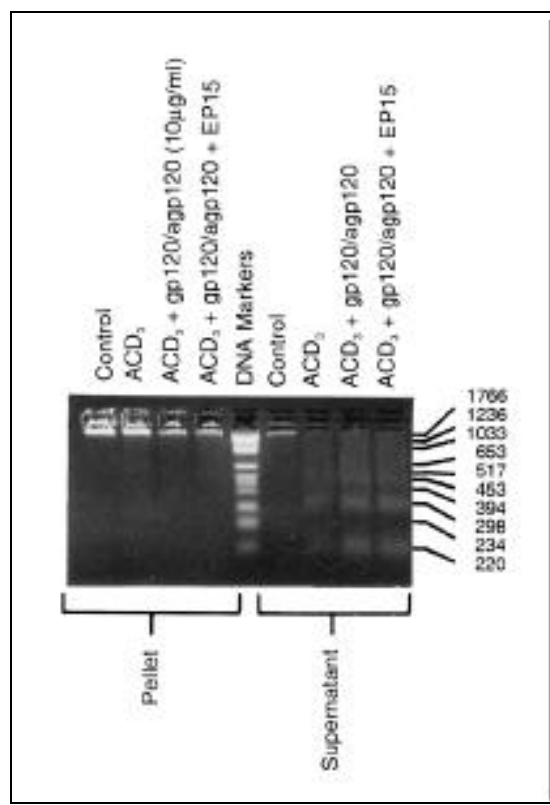

Figure 2. 72-h supernatants (but not pellets) obtained from cultures of anti-CD3-transformed, HIV- derived, PBMCs cells exposed to crosslinked, solid-phase-fixated gp120 protein $(10 \mu \mathrm{g} / \mathrm{mL})$ and anti-gp120 $(10 \mu \mathrm{g} / \mathrm{mL}) \mathrm{im}$ mune complexes, show DNA fragmentation pattern that is the signature of apoptosis. Goatanti-rabbit serum was used to cross-link antigp120 to surface of wells. EP refers to a 15-amino acid peptide representative of the $\beta 2$ domain of MHC class II (investigation unpublished). phase fixation of gp120/anti-gp120 immune complexes was required, goatanti-rabbit serum (GAR; BIONETICS, Charleston, SC, USA) was used (1). Aliquots of cell suspensions were collected subsequent to various incubation intervals for examination for the presence of apoptotic and necrotic forms and for DNA agarose gel electrophoresis (8).

\section{Detection of Nuclease Activity of Recombinant gp120}

Nuclease detection in the gp120BSA preparation by sodium dodecyl sulfate polyacrylamide gel electrophoresis (SDS-PAGE) was carried out according to a well-described method (15) with some minor modifications $(3,4)$, and using DNase I (Boehringer Mannheim) with molecular weight of $34000 \mathrm{Da}$ as a positive control. In addition, because nuclease renaturation of the gp120-BSA preparation (but not the DNase I) proved impossible after SDSPAGE despite the use of numerous renaturation techniques $(3,4)$, we attempted to detect the nuclease in the gp120 preparation in non-denaturing gels (16-18).

\section{Localization of Nuclease Activity with Respect to gp120 Itself}

Immunoprecipitation using ProteinA-Agarose (Oncogene Science, Manhasset, NY, USA) and carried out according to this manufacturer's in-

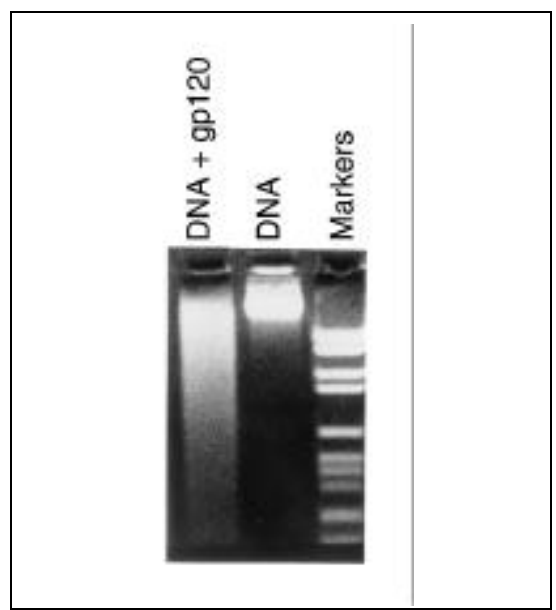

Figure 3. Effect of $1 \mu \mathrm{g}$ gp120 suspension on 1 $\mu \mathrm{g}$ human DNA (lane 1) when co-incubated at $37^{\circ} \mathrm{C}$ for $4 \mathrm{~h}$ and subsequently size-fractionated by DNA agarose gel electrophoresis shows gp120-mediated degradation of the DNA. structions was used to ascertain whether the nuclease activity in the gp120 preparation was functionally distinguishable from the gp120 itself. Fifteen micrograms anti-gp120 antibodies, $4 \mu \mathrm{g}$ gp120 and $30 \mu \mathrm{L}$ of Protein-A-Agarose were incubated in a microcentrifuge tube at $4^{\circ} \mathrm{C}$ on a rocking device for $15 \mathrm{~h}$. The immunoprecipitate was collected in a microcentrifuge at $2500 \mathrm{rpm}$ for $15 \mathrm{~min}$ at $4^{\circ} \mathrm{C}$. The pellet was washed with phosphate-buffered saline (PBS), and then samples of both supernatant and pellet were incubated with $1 \mu \mathrm{g}$ DNA for $4 \mathrm{~h}$ at $37^{\circ} \mathrm{C}$ before DNA gel electrophoresis. Aliquots were also submitted to SDS-PAGE electrophoresis, Western blotting, incubation with anti-gp120 antibodies and subsequent detection of gp120 with the peroxidase-4-chloro-napthol system.

\section{Additional Materials}

All other materials and reagents were of analytical grade and were from standard commercial sources. 


\section{Short Technical Reports}

\section{RESULTS}

\section{Electrophoretic Assessment of gp120 Nuclease Activity}

Resuspended recombinant gp120 (1 $\mu \mathrm{g})$ was shown to have nuclease activity since $(i)$ the 72-h supernatants of transformed mononuclear cells derived from $\mathrm{HIV}^{-}$subjects showed the DNA fragmentation pattern that is the signature of apoptosis (Figure 2), and (ii) 1 $\mu \mathrm{g}$ gp120 suspension incubated with 1 $\mu \mathrm{g}$ human DNA was shown to degrade the DNA as evidenced by a smear on the electrophoresis gel (Figure 3). The nuclease activity was thermolabile, was $\mathrm{Ca}^{+2}$ - and $\mathrm{Mg}^{+2}$-dependent and was inhibited by $\mathrm{Zn}^{+2}$ ions (data not shown). Nuclease activity was also endonucleolytic in nature since the gp 120 suspension was found to cleave the circular plasmid pGEM-3ZDNA (data not shown). Furthermore, the nuclease activity still exerted detectable effects when used at $0.1 \mu \mathrm{g}$ but not at $0.01 \mu \mathrm{g}$.

\section{Electrophoretic Assessment of Nuclease Activity of Recombinantly Produced E. coli Proteins}

Interferon $\gamma$, but not IL-1 $\alpha$, IL-1 $\beta$ and IL-6, (all of which are produced recombinantly by $E$. coli), demonstrated nuclease activity (data not shown).

\section{Attempted Detection of Nuclease Activity of gp120 Preparation in SDS-PAGE and in Non-Denaturing Gels}

Although numerous attempts at protein renaturation $(3,4,13)$ were made following size-fractionation by SDSPAGE, we failed to renature the nuclease fraction of the gp120 preparation. However, including DNaseI as a control nuclease that migrated to the correct position $(33 \mathrm{kDa})$ and demonstrated activity after renaturation confirmed that the system was working. Nuclease activity of the gp120 preparation was verified on a non-denaturing gel, but obviously, due to the limitations of this method, the size of the nuclease could not be determined. Data of these experiments were excluded because they were essentially non-helpful.

\section{Immunoprecipitation of gp120 with Subsequent Analysis of Nuclease Activity and the gp120 Content of the Supernatant and Pellet}

On immunoprecipitation of gp120 with anti-gp120 antibodies and ProteinA-Agarose, the supernatant, but not the pellet, was found to have the nuclease activity (Figure 4A). Western blot analysis of the pellet demonstrated the presence of gp120, anti-gp120 anti-

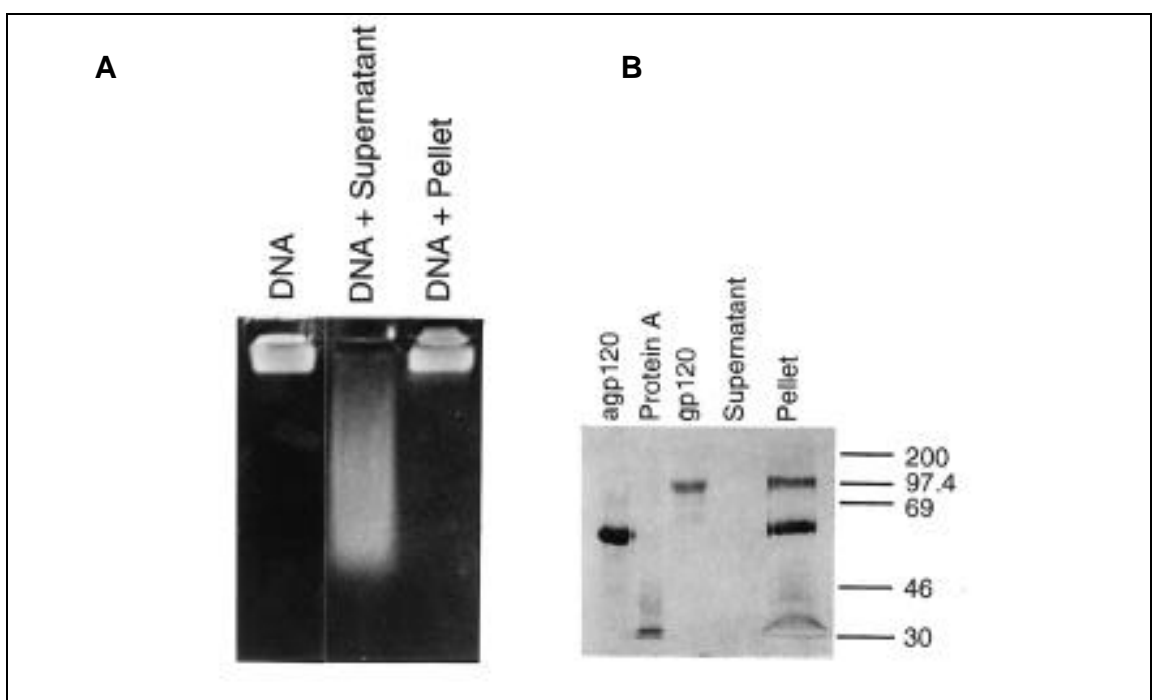

Figure 4. (A) Immunoprecipitation of gp120 $(4 \mu \mathrm{g})$ with anti-gp120 antibodies $(15 \mu \mathrm{g})$ and Protein-AAgarose and subsequent assessment of nuclease activity of the washed pellet and of the supernatant; lane 1: endonuclease buffer plus $1 \mu \mathrm{g}$ DNA; lane 2 : supernatant plus endonuclease buffer plus $1 \mu \mathrm{g}$ DNA; and lane 3: pellet plus endonuclease buffer plus $1 \mu \mathrm{g}$ DNA. (B) Western blot analysis of the pellet and the supernatant. Lane 1: anti-gp120 antibodies alone; lane 2: Protein A alone; and lane 3: gp120 protein alone, served as controls for identifying the contents of lanes 4 and 5 . Units of protein molecular weight markers are expressed in $\mathrm{kDa}$. bodies and Protein-A-Agarose; whereas, the supernatant lane was empty (Figure 4B).

\section{DISCUSSION}

The presence of endonuclease activity in recombinant protein products is clearly of cautionary significance for users investigating putative apoptosis purported to be elicited by such products. In this study, we have demonstrated endonuclease activity in different batch preparations of recombinant gp120 protein, an HIV-1 product incriminated in the pathogenesis of AIDS by virtue of its capacity to prime CD4 T-cells for activation-induced apoptosis (1,5-7,11-13). This process may be aggravated by anti-gp120 antibodies (1) or HIV-1 Tat protein $(10,20)$.

In cultures of cells dying of necrosis, appreciable quantities of DNA are released into the culture medium, where any endonuclease activity is responsible for cleaving the DNA into characteristic 180-200-bp multi-mers, thus simulating death by apoptosis. This appeared to be the case in our study. Similarly, contamination of DNA extracts of normal living cells by trace amounts of culture medium containing endonuclease activity would be expected to have the same effect. Before conclusions can be drawn from the results of culture studies exploring this effect, while not disputing that genuine gp120-induced apoptosis does occur under appropriate circumstances, our findings underline the need for adequate controls in study design to be implemented to exclude the phenomenon we have described.

The identity and molecular weight of the nuclease encountered in our study could not be established, because of its functional sensitivity to the denaturation cycle required for the preparative procedures used. Nevertheless, certain functional characteristics could be inferred indirectly, including its endoactivity, its thermal instability, its $\mathrm{Ca}^{+2}$ and $\mathrm{Mg}^{+2}$-dependence and its $\mathrm{Zn}^{+2}$ sensitivity. These characteristics further compound its similarity to the apoptotic endonuclease (2). Immunoprecipitation wth Protein-A-Agarose and polyclonal anti-gp120 antibodies of 
reconstituted gp120 protein, followed by assay of the supernatant and pellet for DNase activity, demonstrated that nuclease activity was confined to the supernatant only. This was consistent with the subsequent Western blot analysis, which showed the gp120 protein to be confined to the pellet and not to present in the supernatant. Thus, the nuclease activity in the gp120 preparation was functionally distinguishable from the gp120 protein itself.

Since Rohrmann's laboratory has reported nuclease activity in wild-type baculovirus-infected cells (14), the presence of similar endonuclease activity in another baculovirus-derived recombinant protein, the red blood cell protein 4.2 (Pallidin) and its absence from most bacterial-derived recombinant protein products studied, suggests that endonuclease contamination of protein products of insect cell expression systems may occur quite frequently. Since the insect cell system is eminently suitable for the production of many comparatively high molecular weight proteins such as cytokines, which may also be undergoing investigation as putative agents responsible for the induction or prevention of apoptosis, this problem could become quite common if not recognized by the investigators.

\section{REFERENCES}

1.Banda, N.K., J. Bernier, D.K. Kurahara, R. Kurrle, N. Haigwood, R-P. Sekaly and T.H. Finkel. 1992. Crosslinking CD4 by human immunodeficiency virus gp 120 primes $\mathrm{T}$ cells for activation-induced apoptosis. J. Exp. Med. 176:1099-1106.

2.Barry, M.A. and A. Eastman. 1993. Identification of deoxyribonuclease II as an endonuclease involved in apoptosis. Arch. Biochem. Biophys. 300:440-450,

3.Blank, A., J.R. Silber, M.P. Thelen and C.A. Dekker. 1983. Detection of enzymatic activities in sodium dodecyl sulfate-polyacrylamide gels: DNA polymerases as model enzymes. Anal. Biochem. 135:423-430.

4.Blank, A., R.H. Sugiyama and C.A. Dekker. 1982. Activity staining of nucleolytic enzymes after sodium dodecyl sulfate-polyacrylamide gel electrophoresis: use of aqueous isopropanol to remove detergent from gels. Anal. Biochem. 120:267-275.

5.Finkel, T.H., G. Tudor-Williams, N.K. Banda, M.F. Cotton, T. Curiel, C. Monks, T.W. Baba, R.M. Ruprecht and A. Kupfer. 1995. Apoptosis occurs predominantly in bystander cells and not in productively infected cells of
HIV- and SIV-infected lymph nodes. Nature Med. 1:129-134.

6.Fraser, M.J. 1992. The baculovirus-infected insect cell as a eukaryotic gene expression system. Curr. Top. Microbiol. Immunol. 158:131-172

7.Groux, H., G. Torpier, D. Monte, A. Capron and J.C. Ameisen. 1992. Activation-induced death by apoptosis in $\mathrm{CD} 4+\mathrm{T}$ cells from human immunodeficiency virus-infected asymptomatic individuals. J. Exp. Med. 175:331340.

8.Her, E., J. Frazer, K.F. Austen and W.F. Owen. 1991. Eosinophil hematopoietins antagonize the programmed cell death of eosinophils. J. Clin. Invest. 88:1982-1987.

9.Kidd, M. and V.C. Emery. 1993. The use of baculovirus as expression vectors. Rev. Biotechnol. 42:137-159.

10.Li, C.J., D.J. Friedman, C. Wang, V. Metelev and A.B. Pardee. 1995. Induction of apoptosis in uninfected lymphocytes by HIV1 Tat protein. Science 268:429-431.

11.Murhammer, D.W. 1991. The use of insect cultures for recombinant protein synthesis: engineering aspects. Appl. Biochem. Biotechnol. 31:283-310.

12.Pantaleo, G. and A.S. Fauci. 1995. Apoptosis in HIV infection. Nature Med. 1:118-120.

13.Pantaleo, G., C. Graziosi and A.S. Fauci. 1993. The immunopathogenesis of human immunodeficiency virus infection. N. Engl. J. Med. 328:327-325.

14.Rohrmann, G. and B. Moss. 1985. Transcription of vaccinia virus early genes by a template-dependent soluble extract of purified virus. J. Virol. 56:349-355

15.Rosenthal, A.L. and S.A. Lacks. 1977. Nuclease detection in SDS-polyacrylamide gel electrophoresis. Anal. Biochem. 80:76-90.

16.Seki, S., K. Akiyama, W. Sekiko and K. Tsutsui. 1993. Activity gel and activity blotting methods for detecting DNA-modifying (repair) enzymes. J. Chromatogr. 618:147166.

17.Shukla, S.K. and D. McCarthy. 1994. An activity gel assay for the detection of DNA helicases and nucleases from cell-free extracts. Nucleic Acids Res. 22:1626-1631.

18.Spanos, A.D. and U. Hubscher. 1983. Recovery of functional proteins in sodium dodecyl sulfate gels. Methods Enzymol. 91:263277.

19.Terai, C., R.S. Kornbluth, C.D. Pauza, D.D. Richman and D.A. Carson. 1991. Apoptosis as a mechanism of cell death in cultured $\mathrm{T}$ lymphoblasts acutely infected with HIV-1. J. Clin. Invest. 87:1710-1715.

20.Westendorp, M.O., R. Frank, C. Ochsenbauer, K. Stricker, J. Dhein, H. Walczak, KM. Debatin and P.H. Krammer. 1995. Sensitization of $\mathrm{T}$ cells to CD95-mediated apoptosis by HIV-1 Tat and gp120. Nature $375: 497-500$

We gratefully acknowledge the financial support of the Loewenstein Foundation, the $M R C$, the NCA the SAIMR and the University of the Witwatersrand. We are most grateful to Dr. T. Coetzer for her advice and assistance. We are indebted to Dr. Mary Risinger for supplying us with a lyophilized homogenate of Sf9 cells expressing Rho baculovirus-derived $R B C$ protein palladin. Address correspondence to Avri N. Davidoff, Department of Haematology, University of the Witwatersrand Medical School, York Road, Parktown 2193, Johannesburg, South Africa. Internet: 075avri@chiron. wits.ac.za

Received 26 April 1996; accepted 17 January 1997.

\section{Avri N. Davidoff and B.V. Mendelow University of the Witwatersrand and South African Institute for Medical Research Johannesburg, South Africa}

